\title{
The Effect of Portfolio Assessment on General English Learners' Locus of Control and Achievement
}

\author{
Majid Elahi Shirvan
}

University of Bojnord, Iran

Seyyed Ehsan Golparvar

University of Bojnord, Iran

\section{Introduction}

An integral part of any teaching program is assessment. Assessment refers to gathering information and making judgments about a language learner's knowledge of a language and the ability to use it (Chapelle and Brindley, 2002). Contemporarily, in line with a shift from traditional, teacher-centered instruction to more student-centered pedagogy, there is also an attempt to practics alternatives to traditional, standardized assessment. The goal is to tap into the process of learning as well as its product and integrate teaching and testing activities (Yurdabakan and Erdughan, 2009).

One of the innovations in the framework of alternative assessment is portfolio assessment. A portfolio simply is a collection of students' work. Portfolios have been extensively used by painters, artists, writers, and photographers to display their vocational and acquired skills (Zollman and Jones, 1994). Language teaching has also made use of portfolios. Many studies have been carried out to investigate the effect of portfolios on foreign language skills (e.g., Wang and Liao, 2008; Marefat, 2004;Paesani, 2006; and Hirvela and Sweetland, 2005). There are also some attempts to explore the effect of portfolio assessment on psychological constructs. Atai and Nikuinezhad (2006) examined the effect of portfolio assessment on learners' awareness of metacognitive reading strategies and their motivation for reading. In both cases portfolio assessment had a positive effect.

However, the extent to which portfolio assessment might affect General English achievement and locus of control of foreign language learners has not been examined. The present study aims at investigating the effect of portfolio assessment on GE students' achievement and their LOC. Furthermore, it tries to shed light on GE students' perceptions of portfolio assessment. 


\section{Review on Portfolio}

A serious shortcoming of traditional tests is that they are administered once or twice in a course and fail to pay attention to students' performance throughout the term. Therefore, they do not fully reflect students' knowledge, abilities, skills, needs, and interest, and they cannot fully help teachers and syllabus designers to make sound decisions concerning educational changes. These traditional paperand-pencil tests are product-oriented and fail to show what actually happens in an EFL classroom. They measure language learners' capability of recalling and reproducing specific knowledge, concepts, and lower-level skills instead of their ability to produce and apply knowledge, significant higher-level skills, and concepts to real-life contexts (Wiggins, 1990; Crosby, 1997; Cohen, 2001). Genesee and Upshur (2004) have asserted that in traditional assessment, students are just objects in the hands of teachers and/or test designers and their role in the process of assessment is weak. Rudman (1989) held that assessment and teaching are not separate from each other; testing is an inseparable part of teaching. It is to the benefit of both language teachers and students to link testing to teaching.

Undoubtedly, EFL learners have their own interests, needs, abilities, strengths, and weaknesses. Therefore, one single method of assessment does not suffice to get a comprehensive picture of students' progress. Teachers should resort to manifold assessment tools to have a clear and comprehensive understanding of cognitive, affective, and behavioral aspects of their students. As a consequence, instructors need to administer assessment tools at different points of time to achieve a better view of students' learning process (Wiggins, 1989; Moya\& O'Malley, 1994). The concept of alternative assessment has been related to foreign language teaching because it concentrates on what learners are able to do with the language rather than what they can remember or reproduce. As a result, it does not foster rote memorization or passive test taking. Alternate assessment attaches importance to the final product as well as the learning process.

Portfolio assessment is one of the most widely used forms of alternative assessment. Traditionally, architects, models, and other artists make use of portfolios as a means of sample work to show to customers and their employees (Valencia \&Calfee, 1991). Collins (1992) contended that portfolios have been widely used as an alternative to standardized assessment,. Portfolios are more than a collection of students' work, and represent EFL learners' personalized and longitudinal efforts. As Fredrick and Shaw (1996) maintained, a portfolio is a purposeful, systematic, and selective collection of a learner's work showing his or her efforts and accomplishments in a particular domain. O'Malley and Pierce (1996) pointed out to the three most common types of portfolios, namely showcase 
portfolio, collection portfolio, and process-oriented portfolio. Showcase portfolio is a collection of a student's best or most desired work. Here, only complete work is included, so the product of learning is important. Collection portfolio includes everything a learner does throughout a course. All work, from the weakest to the best, are incorporated; therefore, collection portfolio emphasizes the process of learning. Evaluation portfolio, also called assessment portfolio, requires learners to choose their work to be assessed based on criteria set by the teacher. It is used for grading purposes.

It should be highlighted that while a portfolio is a collection of a student's work, portfolio assessment is the process of producing, collecting, and evaluating portfolios. This process sheds light on learners' growth and accomplishment. Portfolio assessment involves student-teacher interactions and conferences during which they talk about the problems faced and strategies to perform better in future (Moya\& O'Malley, 1994). Moya\& O'Malley (1994) see several key features in portfolio assessment: first it is comprehensive because it shows both the breadth and depth of learners' knowledge, second it is systematic and predetermined, because the evidence is supposed to be meaningful to students, teachers, and parents, and finally it is informative, that is, the evidence needs to be meaningful for students, teachers, and parents.

A salient step in the process of portfolio assessment is conferencing. It is an effective strategy that is in line with the philosophy of portfolio, which is shared and active assessment. Conferencing involves discussions between a teacher and students on their work for determining goals for future. These conferences help teachers understand the approaches, processes, and strategies learners use to perform their school work. Furthermore, conferences give learners a sense of ownership and involvement in the learning and assessment process (Farr \& Tone, 1998).

In the process of learning a foreign language, students attribute their success and failure to certain external and/or internal factors. Locus of Control (LOC) which stems from Rotter's (1954) Social Learning Theory shows that a person's expectancy of an outcome will predict behavior in a particular situation. According to Rotter (1966), learners with internal locus of control attribute their failure and success to their own behavior or personal characteristics. Individuals with internal LOC believe that their behavior can affect the outcome, while individuals with external LOC think that external factors, such as other people or factors beyond their control, determine the outcome of their behavior (Rotter, 1966). The effect of LOC on GE achievement of university students has already been studied by Ghonsooly and Elahi (2010) who found that there is a significant correlation between university students' LOC and their scores in their GE courses. According 
to their study, Engineering students who favored internal locus of control got better scores in their General English compared to Humanities students who were externalizers and were poor in their GE. However, the effect of portfolio assessment on LOC is unexplored and is the main purpose of this study.

\section{Method}

\section{Participants}

A total of eighty university students participated in this study. They were (randomly) divided into an experimental and a control group. The experimental group consisted of 40 students ofengineering and sciences of Ferdowsi University of Mashhad, Iran. The control group similarly comprised 40 students ofengineering and sciences of the same university. The participants' age ranged from 18 to 22 . Out of eighty students, 58 were female and the rest were male. All of them spoke Persian as their mother language. In order to divide the participants randomly into two groups of control and experimental, first the participants' scores on the pretest Internal Control Index (Duttwieler, 1984) was ranked from the highest to the lowest. Then the one with highest score was assigned to the first group and the one with the second highest score was assigned to the second group and this process continued to the one with the lowest score. In order to make sure that the difference between the mean scores is not significant and the two groups are the same with regard to the construct tested, an independent samplest-test was used.

\begin{tabular}{|c|c|c|c|c|}
\hline Groups & $\mathrm{N}$ & Mean & Std.Deviation & Std.error Mean \\
\hline 1.00 & 40 & 34.50 & 6.15 & 1.09 \\
\hline 2.00 & 40 & 34.03 & 6.25 & 1.08 \\
\hline
\end{tabular}

Table 1. Descriptive statistics of the LOC mean scores

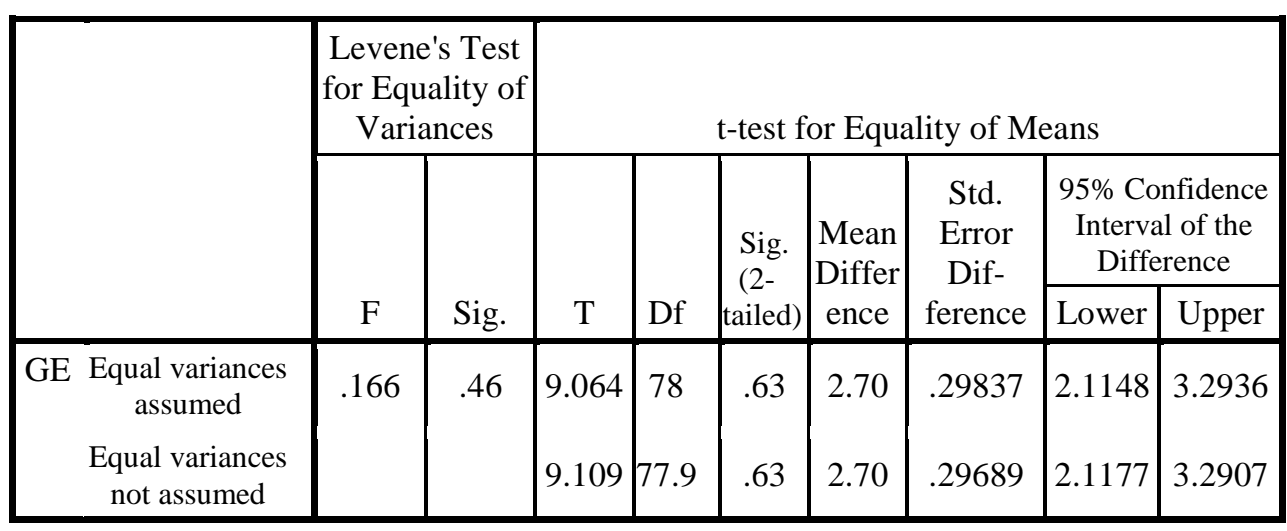

Table 2. Determining the significance of the mean scores difference in LOC 
The results of this test revealed that the two groups did not significantly differ from each other in terms of their performance on the T-test. It means that the participants of the two groups were equal with regard to their GE ability.

\section{Instruments}

Several instruments were used in this study including, Internal Control Index, Reading Strategy Log, Attitude and Motivation Questionnaire:

\section{Internal Control Index}

The first instrument used in this study was the Persian version of the Internal Control Index (Ghonsooly\&Elahi, 2010) to measure the participants' locus of control. The English version of the Internal Control Index (Duttwieler, 1984) was developed to measure where a person expects to gain reinforcement. This scale has twenty eight five-point Likert-type items that produce a possible range of scores from twenty eight to 140 . Higher scores represent internal LOC while lower scores represent external LOC. Ghonsooly and Elahi (2010) calculated the Cronbach's alpha of the translated questionnaire to check its reliability. The result was a coefficient of 0.83 . In order to ensure the construct validity of the instrument, they used a principle component analysis which yielded eight factors with eight values greater than one. The factors include the need to be encouraged, reliance on one's attitude, interest in administrative jobs, effort to reach desirable goals, undecidedness, the need to consult for making decisions, being responsible for desirable events, and self-expression (Hosseini\&Elahi, 2010).

\section{Reading Strategy Log}

The second instrument was Reading Strategy Log. At the outset of the course, the second researcher introduced the purpose and the fundamental requirements of the portfolio to the students and the weight it would have in their final score. The portfolio contents included eight reading passages related to their General English courses. The Reading Strategy Log (Attai\&Nikonezhad, 2006) for each passage was used to monitor students' reading comprehension and strategy use. In other words, it was used for metacognitive reflection and self-assessment purposes.

\section{Attitude and Motivation Questionnaire}

The third instrument was the Attitude and Motivation Questionnaire developed by Attai and Nikonezhad (2006)to determine students' perception of the portfolio assessment of their reading competence and their motivation for this approach. 
This questionnaire includes 17 Likert-type items tapping on such issues as learners' awareness of the course and assessment objectives, evaluation of their progress and assessment standards, and their reactions to the application portfolios for learning and assessment purposes. The three-point Likert-type items of this questionnaire were followed by an open-ended question in order to elicit students' detailed opinions regarding using portfolios as a tool for measuring reading ability (Attai\&Nikonezhad, 2006).

\section{Students' Task Marking Sheet}

This sheet was developed to let students grade their own portfolio pieces according to predetermined criteria. It comprised five items yes-no items related to learners' evaluation of their reading process. Students were supposed to answer three items for all of the eight reading passages. Furthermore, there are two parts in which students and their teacher were asked to give a holistic score for the mentioned items. There was also an open-ended question asking students to elaborate on their opinions on this particular learning experience and way of assessment of their reading comprehension.

\section{Teachers' Evaluation Checklist (Teachers' Task Evaluation Sheet)}

Attai and Nikonezhad (2006) developed a checklist for teachers to evaluate students' final portfolios. Similarly, there were five yes-no items about the process of reading comprehension for all of the texts. There was also a part for teachers to assign a holistic score for these items.

\section{Interview}

Finally a semi-structured interview was conducted by the second researcher. The 6 questions of this interview were taken from Yurdabakan and Erdoghan (2009). The questions deal with the purposes for preparing portfolios, the standards set for arranging materials in portfolios, students' favorite product, students' opinions about the preparation of portfolios, the challenges they faced in this process, and learners' final evaluation of their achievement of predetermined goals.

\section{Reading Materials}

The reading materials specified for the two groups of students included English for the Students of Engineering and English for the Students of Science. The two books published by the Iranian Ministry of Science are taught across Iranian universities and comprise 8 units that were taught in 15 ninety-minute sessions. 


\section{Data Collection and analysis}

The experimental treatments were carried out according to the stages shown in Figure 1 for 12 weeks. In the first session, concepts like portfolio, portfolio components, portfolio tasks and homework, preparation of a portfolio and portfolio assessment were dwelled upon; the purposes of portfolio assessment were discussed and sample examples were demonstrated to the students in the treatment group. In the second session, educational objectives of portfolio assessment were explained and student studies related to those objectives were defined. They were reminded that their portfolios would be towards developing their skills in English (reading, listening, writing, and speaking) and the students were told that, besides these general goals, each portfolio would also reflect the students' individual goals or objectives. Later, the students were asked to write down the goals for their own portfolios and for this, while writing their objectives of their portfolios, they were informed to take into account difficulties they had in those skills and the things they would like to improve with the help of this portfolio study. In the third session, issues like the portfolio categories and the selection of learning products that would go into their portfolios, the place to keep the portfolios and evaluation criteria were discussed together with the students and a page of "Portfolio Guide" was prepared and posted on a wall where students could read and refer to it anytime they wanted. In the fourth session, the purpose and preparation of rubrics that are aimed to evaluate learning products were explained and under the

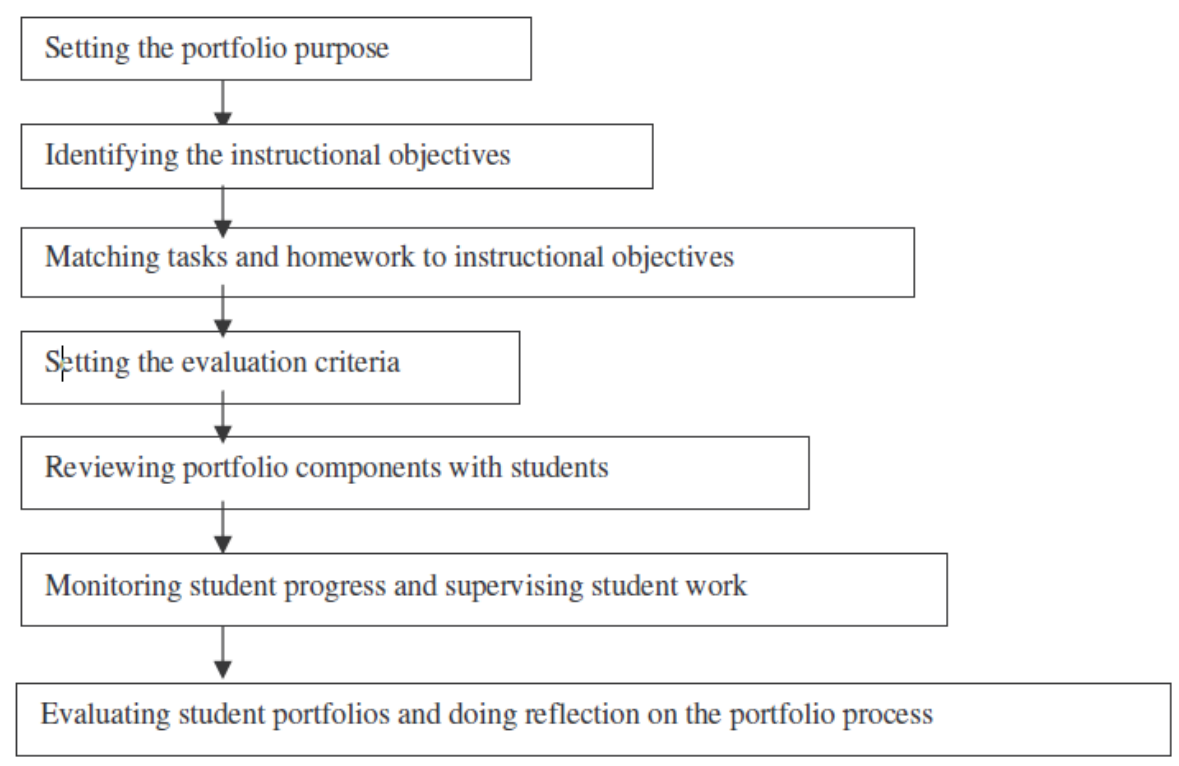

Figure 1. Stages of portfolio process up to here 
1. Read the title

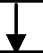

2. Anticipate what the topic may be about

3. Read the First Paragraph

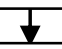

4. Find the supporting and main ideas

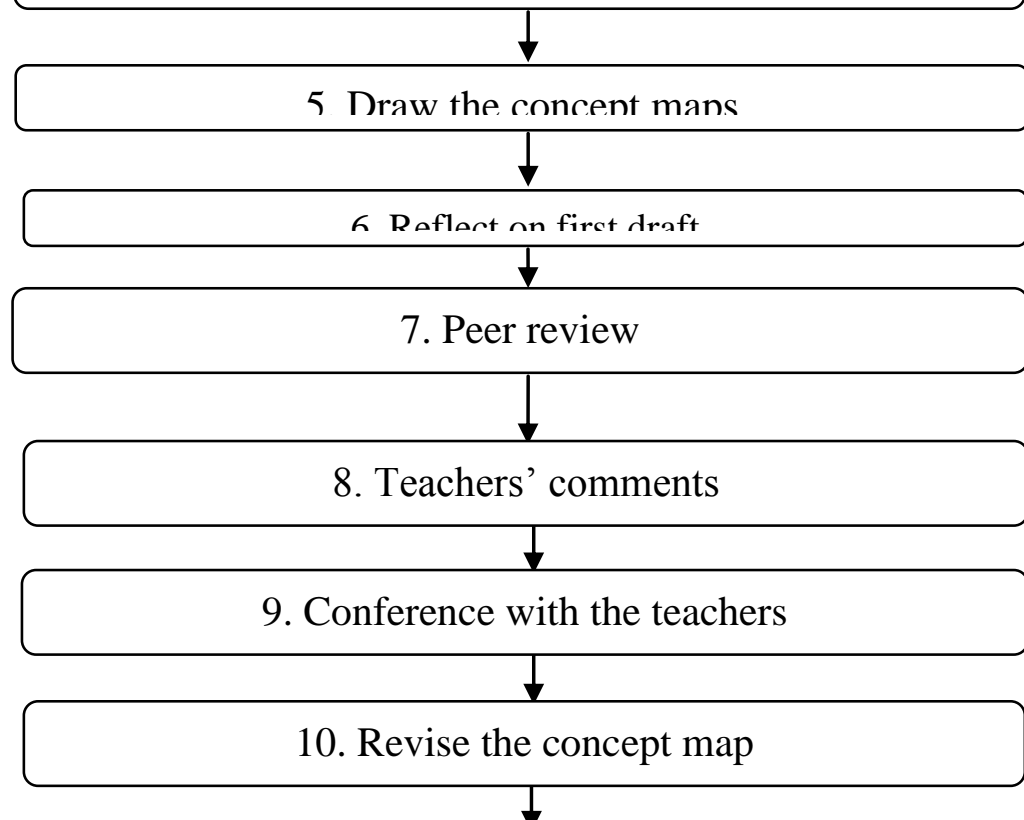

11. Anticipate what the next paragraph may be about

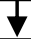

12. Repeat Procedures for each paragraph to the

13. Shape the final concept map

14 Answer the final true/false multinle choice auestions

15. Collect the final draft in portfolio

Figure 2. Stages of reading portfolio 
supervision of the teacher, the writing rubric that would be used to evaluate the ritten products of students was prepared together with students. In the fifth session, the students were asked to evaluate their written products and they were asked to explain how they scored their papers and what scores they gave. They were given the opportunity of self-evaluation. In the sixth session, owing to the requests of students, a review was done in class.

From the seventh session up to the end of the course, in each session students were encouraged to read the title, anticipate what the topic may be about, read the first paragraph ( the introduction paragraph), find out the main idea and the supporting ideas, draw concept maps, and reflect on their first drafts. Furthermore, students reviewed their peers' drafts, and they had conferences with the teacher who gave his comments on the drafts leading to revision of their concept maps. The same procedure was practiced for the rest of the paragraphs. Then, students were asked to draw the final concept map and answer the final true-false and/or multiplechoice questions. In the end, the final drafts placed in portfolios were collected and the students filled in the Students' Strategy Log and the Students' Task Marking Sheet for each passage.

In order to analyze the data, Man Whitney $\mathrm{U}$ test, Wilcoxon, T-test, and Chi Square were used. The analysis was conducted by the Statistical Package for Social Sciences (SPSS).

\section{Results}

In order to answer the first research question concerning the effect of reading portfolios assessment of GE learners' reading achievement the researchers used an independent T-test. Table below illustrates that the experimental groups' mean score is higher than that of the control one.

\begin{tabular}{|ll|l|l|l|l|}
\hline \multicolumn{1}{|c|}{ Groups } & $\mathrm{N}$ & Mean & Std. Deviation & Std. Error Mean \\
\hline GEA & Experimental & 40 & 31.20 & 1.94 & .214 \\
& Control & 40 & 24.50 & 1.76 & .205 \\
\hline
\end{tabular}

Note: GAE $=$ General English Achievement

Table3. Description of GEA mean scores of both groups

Table 4 indicates that the difference in mean scores shows that there is a significant difference in scores for the experimental $(M=31.20, S D=.24)$ and control groups $(M=24.50, S D=.20), t(78)=9.06, p<.05$. 


\begin{tabular}{|c|c|c|c|c|c|c|c|c|c|c|}
\hline & \multicolumn{2}{|c|}{\begin{tabular}{|c|} 
Levene's Test \\
for Equality of \\
Variances
\end{tabular}} & \multicolumn{7}{|c|}{ t-test for Equality of Means } \\
\hline & & \multirow[b]{2}{*}{$\mathrm{F}$} & \multirow[b]{2}{*}{ Sig. } & \multirow[b]{2}{*}{$t$} & \multirow[b]{2}{*}{ Df } & \multirow[b]{2}{*}{$\begin{array}{l}\text { Sig. (2- } \\
\text { tailed) }\end{array}$} & \multirow[b]{2}{*}{$\begin{array}{c}\text { Mean } \\
\text { Difference }\end{array}$} & \multirow[b]{2}{*}{$\begin{array}{l}\text { Std. Error } \\
\text { Difference }\end{array}$} & \multicolumn{2}{|c|}{$\begin{array}{l}\text { 95\% Confidence } \\
\text { Interval of the } \\
\text { Difference }\end{array}$} \\
\hline & & & & & & & & & Lower & Upper \\
\hline & $\begin{array}{l}\text { Equal variances } \\
\text { assumed }\end{array}$ & \multirow[t]{2}{*}{.166} & \multirow[t]{2}{*}{.684} & 9.06 & 78 & .000 & 2.70427 & .29837 & 2.11485 & 3.29369 \\
\hline & $\begin{array}{l}\text { Equal variances } \\
\text { not assumed }\end{array}$ & & & 9.109 & 78.992 & .000 & 2.70427 & .29689 & 2.11776 & 3.29078 \\
\hline
\end{tabular}

Table 4. Determining the significance of the mean scores difference in GEA

The researchers, in order to answer the second question, with regard to the effect of portfolios on GE learners' locus of control, compared the LOC mean scores of both groups first. Table 5 shows that the LOC mean score of the experimental group (98.20) is higher than that of the control group (62.50).

\begin{tabular}{|c|c|c|c|c|c|}
\hline \multicolumn{2}{|r|}{ Groups } & $\mathrm{N}$ & Mean & Std. Deviation & Std. Error Mean \\
\hline \multirow[t]{2}{*}{$\overline{\mathrm{LOC}}$} & Experimental & 40 & 98.20 & 1.94 & .222 \\
\hline & Control & 40 & 62.50 & 1.76 & .210 \\
\hline
\end{tabular}

Table 5.Description of LOC mean scores of both groups

Therefore, an independent t-test was used to see whether such a difference in LOC mean scores is significant or not.

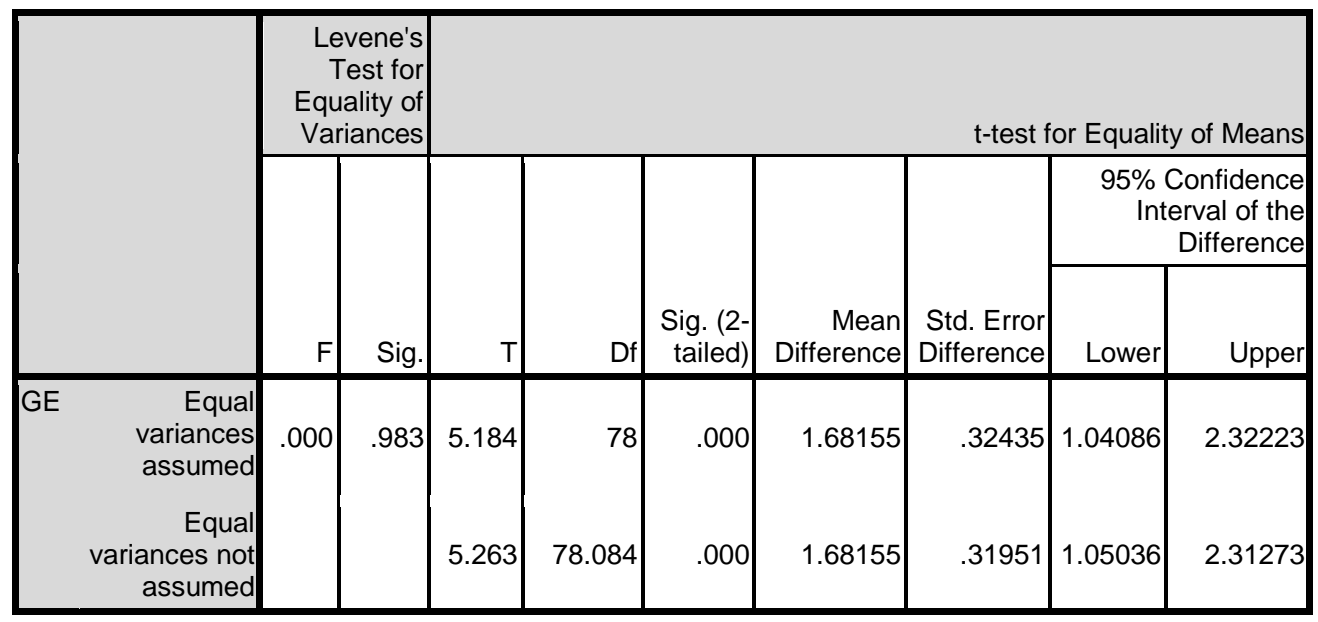

Table 6. Determining the significance of the mean scores difference in LOC 
Table 6 points out that there is a significant difference in LOC mean score of the experimental group $(M=98.20, S D=.22)$ and that of the control group $(M=62.50$, $S D=1.76), t(78)=5.18, P<.05$.

\section{Results concerning the performance of the groups in LOC sub-parts}

Since the distribution of scores in all LOC sub-parts were not normal, MannWhitney test which is the non-parametric equivalent to the independent-samples ttest was used to see if the experimental group outperformed the control group in writing sub-skills. Table 7 shows the LOC orientation of the control and experimental groups on each of the sub-part in the post-administration of the LOC test.

\begin{tabular}{|l|l|l|l|l|}
\hline Sub-factors & Groups & N & Mean-rank & $\begin{array}{l}\text { Sum of } \\
\text { Ranks }\end{array}$ \\
\hline The need to be & Experimental & 40 & 23.00 & 520.00 \\
encouraged & Control & 40 & 31.50 & 740.00 \\
\hline reliance on one's attitude & Experimental & 40 & 22.00 & 480.00 \\
& Control & 40 & 30.50 & 710.50 \\
\hline Effort to reach desirable & Experimental & 40 & 24.00 & 540.00 \\
goals & Control & 40 & 30.00 & 640.00 \\
\hline self-expression & Experimental & 40 & 22.00 & 630.00 \\
& Control & 40 & 31.00 & 780.00 \\
\hline Interest in administrative & Experimental & 40 & 25.00 & 470.00 \\
jobs & Control & 40 & 32.50 & 720.00 \\
\hline the need to consult for & Experimental & 40 & 21.00 & 510.00 \\
making decisions & Control & 40 & 30.00 & 720.00 \\
\hline being responsible for & Experimental & 40 & 22.00 & 630.00 \\
desirable events & Control & 40 & 31.00 & 750.00 \\
\hline
\end{tabular}

Table 7. Mann Whitney U test for student' responses to the sub-parts of LOC

To see whether the differences in the mean ranks are statistically significant Table 8 should be examined.

\begin{tabular}{|l|c|c|c|c|c|c|c|}
\hline & NBE & ROA & ERDG & SE & IAJ & NCMD & BRDE \\
\hline $\begin{array}{l}\text { Wilcoxon } \\
\text { W } \\
\text { Z }\end{array}$ & 520.000 & 480.000 & 540.000 & 630.000 & 470.000 & 510.000 & 630.000 \\
\hline $\begin{array}{l}\text { Asymp.Sig. } \\
\text { (2-tailed) }\end{array}$ & 0.35 & .000 & .002 & .001 & .000 & .001 & .003 \\
\hline
\end{tabular}

Note: $\mathrm{NBE}=$ The Need to Be Encouraged, ROA=Reliance on One's Attitude, ERDG= Efforts to Reach Desirable Goals, SE= Self-Expression, IAJ= Interest in Administrative Jobs, NCMD= The Need to Consult for Making Decisions, BRDE= Being Responsible for Desirable Events.

Table 8. Wilcoxon test for students' responses to sub-parts of LOC 
The U-values revealed that there were statistically significant differences between the groups in the sub-parts of LOC (the p-value is less than .05). As illustrated in the Table above, the experimental group learners showed improvement in these sub-parts of LOC. Therefore, it is proved that portfolio assessment can affect the GE learners positively in terms of LOC subparts.

\title{
Interview Results
}

The results of the interview indicated that nearly all of the interviewees (9 out of 10) believed that portfolio assessment had a great impact on their reading ability. Saeed, one of the interviewers said:

\begin{abstract}
"The portfolio program helped me to read better by giving me more motivation and confidence in writing. I believe my most noticeable improvement in terms of reading was about organization; how to start reading a text, how to contemplate the topic of the text and the structure of the paragraph, how to consider metadiscourse markers while reading the text, and how to see a text holistically as a discourse."
\end{abstract}

Eight of them asserted that finding the main and supporting ideas by themselves and then justifying their concept maps, when they talked in pairs, not only could give them a good sense of encouragement but also helped them to express their own attitudes. This is manifested in the following excerpts taken from one of the participants' conversation transcripts.
"Before whenever I wanted to do any reading activities I was not sure whether my ideas are reliable or not because I had no chance to air them. However, during the semester I had this opportunity to first think about the justification of my ideas, in the form of concept maps, and then share them with others and express them so that I feel assured they are reliable."

Moreover, eightparticipants said that reflecting on the concepts maps of the paragraphs and then reviewing them with their peer classmates gave them a sense of responsibility to be able to justify their own opinions. This is shown in the following interview data taken from one of the interviewers: 
"Before being introduced with the process of concept mapping and portfolio, I did not think that I could be responsible for my own opinions on what the paragraphs say. When I talked to Ali, my classmate, into accepting my ideas on the structure of the paragraph, I helped me to manipulate my ideas better and feel more responsible for my class activities."

Furthermore, seven of the interviewees mentioned that sharing their ideas with their classmates and the teacher helped them to complete their portfolio better and reach better conclusions.

"Portfolios helped me to find my goal while doing reading activities. It helped me to integrate better with the writer and find out how I can manipulate the process of reading comprehension. In other words, I now know what comprehension means."

In order to compare the degree of the experimental group learners' attitudes towards reading comprehension through portfolio assessment the researchers ran a chi-square on the number of responses: strongly agree, agree, and disagree.

\begin{tabular}{|l|l|l|l|l|l|}
\hline Choices & 1 (disagree) & 2 (agree) & $\begin{array}{l}3 \text { (Strongly } \\
\text { agree) }\end{array}$ & Chi-square & Sig. \\
\hline Frequency & 4 & 8 & 28 & $\mathrm{X} 2=19.823$ & .000 \\
\hline
\end{tabular}

Table 9. Chi-square Test for students' attitudes towards portfolios

In order to go deeply into the experimental learners' perceptions of portfolio assessment in reading comprehension after the end of the treatment, the researchers tabulated the learners' responses to all the items of the questionnaire in Table 10.

\begin{tabular}{|l|c|c|c|c|c|}
\hline \multicolumn{1}{|c|}{ Items } & S.A & A & D & M & SD \\
\hline $\begin{array}{l}\text { 1. I know what the purpose of portfolio } \\
\text { assessment is }\end{array}$ & 18 & 10 & 12 & 2.12 & .42 \\
\hline 2. I do self-assess my reading activities & 29 & 9 & 2 & 2.67 & .55 \\
\hline $\begin{array}{l}\text { 3. My gradual progress during the term is } \\
\text { assessed }\end{array}$ & 25 & 3 & 2 & 2.56 & .47 \\
\hline $\begin{array}{l}\text { 4. I can understand my strengths and } \\
\text { weaknesses in reading }\end{array}$ & 22 & 12 & 6 & 2.23 & .57 \\
\hline 5. I am involved in the learning process & 26 & 12 & 2 & 2.58 & .63 \\
\hline $\begin{array}{l}\text { 6. I do self-assess my progress after doing } \\
\text { each reading }\end{array}$ & 23 & 13 & 4 & 2.25 & .61 \\
\hline
\end{tabular}




\begin{tabular}{|l|c|c|c|c|c|}
\hline 7. I try to work on my area of weakness & 20 & 12 & 8 & 2.26 & .44 \\
\hline $\begin{array}{l}\text { 8. I am more motivated to read through } \\
\text { portfolios }\end{array}$ & 32 & 6 & 2 & 2.81 & .58 \\
\hline 9. I am responsible for my own learning & 31 & 6 & 3 & 2.79 & .63 \\
\hline $\begin{array}{l}\text { 10. I am more interested in doing the } \\
\text { reading through portfolio assessment } \\
\text { compared to traditional testing }\end{array}$ & 26 & 12 & 2 & 2.58 & .55 \\
\hline $\begin{array}{l}\text { 11. My final grade in reading skill is } \\
\text { indicative of my real ability in reading }\end{array}$ & 12 & 2 & 26 & 2.02 & .49 \\
\hline $\begin{array}{l}\text { 12. Reading skills and strategies are } \\
\text { enhanced in portfolio assessment }\end{array}$ & 28 & 8 & 4 & 2.62 & .52 \\
\hline $\begin{array}{c}\text { 13. I do suggest portfolio assessment for } \\
\text { reading comprehension }\end{array}$ & 28 & 9 & 3 & 2.62 & .56 \\
\hline
\end{tabular}

Table 10. Chi-square Test for students' attitudes towards portfolios items

\section{Discussion}

In line with the previous studies on the effect of portfolio assessment on foreign language skills mentioned in the review of literature like Marefat (2004), Paesani (2006), Hirvela and Sweetland (2005) and Atai and Nikuinezhad (2006), the present study highlighted such effect on GE learners' achievement. Atai and Nikunezhad(2006), for example, found that portfolio assessment can improve EFL learners' motivation and metacognitive reading strategies to reach higher achievement in reading comprehension skills. In the present study, we also found portfolio assessment influencing the GE learners' LOC.

Exploring the findings of the present research through the eye of motivation, we think that the higher LOC orientation of EFL learners caused by portfolio assessment might lead to higher levels of motivation. Williams and Burden (1998) and Jarvis (2005) defined LOC as cognitive source of Motivation. In other words, the higher levels of LOC will lead to higher levels of motivation. Therefore, it can be inferred that portfolio assessment could indirectly boost GE learners' motivation. Such inference can be supported by the results of the data analysis of the experimental learners' attitude toward portfolio assessment and also their interviews. The results related to item 8 of the questionnaire indicated that 32 out of 40 learners were more motivated to read through portfolios.

As mentioned in the review of literature, Ghonsooly and Elahi's (2010) investigation of the effect of LOC on University students' General English Achievement showed that first there is a significant and positive relationship between university students' LOC and their general English achievement. Furthermore, Hosseini and Elahi's (2010) exploration of the effect of LOC on EFL 
reading achievement confirmed such an effect.The researchers found that LOC orientation of GE learners can be improved by alternative assessments such as portfolio assessment. In other words, through using portfolio assessment GE teachers can inculcate a sense of responsibility in their learners so that they can improve their achievements in GE. Such interpretation can be supported by the findings related to the attitude about portfolio assessment questionnaire. The findings related to item 9 showed that 31 out of 40 felt responsible for their own learning through portfolio assessment. In addition, the results of the interviews showed that 8 out of the 10 learners interviewed asserted that the portfolio assessment approach gave them a sense of responsibility to be able to justify their own opinions.

\section{References and notes:}

Atai, M. R., \&Nikuinezhad, F. (2006). The effect of portfolio assessment on metacognitive reading strategy awareness of Iranian EFL students. IJLA, 9(2), 1-25.

Chapelle, C. A., \&Brindley, G. (2002). Assessment, In N. Schmitt, An introduction to applied linguistics. London: Arnoold.

Cohen, A.D. (2001). Second language assessment.In M. Celce-Murcia (Ed.), Teaching English as a second or foreign language (3rd ed., pp.515-534). United States: Heinle\&Heinle.

Collins, A. (1992). Portfolios for science education: Issues in purpose, structure, and authenticity. Science Education, 79 (4):451-463.

Crosby, C. (1997). Portfolio assessment in the Korean ESL writing classroom.Thai TESOL Bulletin, 10(2). Retrieved November 13, 2004, from http: // www. thaitesol.org/bulletin/1002/100204.html

Duttweiler, P. C. (1984). The Internal Control Index: A newly developed measure of locus of control. Educational and PsychologicalMeasurement, 44, 209-221.

Farr, R., \& Tone, B. (1998).Portfolio and performance assessment: Helping students evaluate their progress as readers and writers (2nd ed.). United States: Harcourt Brace \& Company.

Frederick, L.R., \& Shaw, E.L.(1996). A survey of the use of portfolios in selected public elementary schools. (Report No. TM 026 379). Paper presented at the Annual Meeting of the Mid-South Educational Research Association, Tuscaloosa. (ERIC Document Reproduction Service No. ED 406 428)

Genesee, F., \& Upshur, J.A. (2004).Classroom-based evaluation in second language education. In J.C. Richards (Series Ed.), Cambridge Language Education (8th ed.).Cambridge: Cambridge University Press.

Ghonsooly, B., \&Elahi, M. (2010). Validating locus of control questionnaire and examining itsrelation to general English achievement. Journal of Teaching Language Skills, 2(1), 117-143.

Hirvela, A. \&Sweetland, Y. L. (2005).Two case studies of L2 writers' experiences across learning-directed portfolio contexts.Assessing Writing, 10 (3), 192-213.

Hosseini, A., \&Elahi, M. (2010).On the alleged relationship between LOC, L2 reading achievement, and use of language learning strategies.Ferdowsi Review, 1, 21-47.

Marefat, F. (2004). Portfolio revisited. Iranian Journal of Applied Linguistics, 7(2), 79-96.

Moya, S., \& O'Malley, J. M. (1994).A portfolio assessment model for ESL.The Journal of Educational Issues of Language Minority Students, 13, 13-36. 
O'Malley, J. M., \& Pierce, V. L. (1996).Authentic Assessment for English Language Learners. Reading, MA: Addison-Wesley.

Paesani, K. (2006). Exercises de style: Developing multiple competencies through a writing portfolio. Foreign Language Annals, 39(4), 618-39.

Rotter, J. B. (1954).Social learning and clinical psychology. New York: Prentice Hall.

Rotter, J. B. (1966). Generalized expectancies for internal vs. external control of reinforcement. Psychological Monographs, 80, 1-28.

Rudman, H.C. (1989). Integrating testing with teaching.Practical Assessment, Research \& Evaluation, 1(6).Retrieved August 7, 2006, from http:/ /paperonline.net/getvn. asp? $\mathrm{v}=1 \& \mathrm{n}=6$

Valencia, S.W., \&Calfee, R. (1991).The development and use of literacy portfolios for students, classes, and teachers.Applied Measurement in Education, 4(4), 333-345

Wang, Y. H. \& Liao, H. C. (2008). The application of learning portfolio assessment for students in the technological and vocational education system. Asian EFL

Wiggins, G. (1990). The case for authentic assessment.Practical Assessment, Research \& Evaluation, 2(2). Retrieved August 7, 2006, from http://paperonline.net/getvn.asp? $\mathrm{v}=2 \& \mathrm{n}=7$

Yurdabakan, I., \&Erdoghan, T. (2009). The effect of portfolio assessment on reading, listening, and writing skills of secondary school prep class students. The Journal of International Social Research, 2(9), 526-538.

Zollman, A. \& Jones, D. L. (1994).Accommodating assessment and learning: Utilizing portfolios in teachers education with preserviceteachers. Paper presented at the Annual Conference of the Research Council on Diagnostic and Prescriptive 


\title{
Appendix B
}

\section{Interview Guide}

1. Do you think that your reading ability improved as a result of the portfolio assessment? 2. Do you think that the sub- parts of locus of control improved as a result of the portfolio program?

3. Which sub-part of locus of control do you think improved most/least as a result of the program?

4. What is your attitude toward portfolio use?

5. What aspect of portfolio assessment you liked most/least?

\section{Summary}

\section{The Effect of Portfolio Assessment on General English Learners' Locus of Control and Achievement}

\author{
Majid Elahi Shirvan \\ University of Bojnord, Iran
}

\author{
Seyyed Ehsan Golparvar \\ University of Bojnord, Iran
}

Portfolio assessment as an alternative to assessing L2 competence is an interesting endeavour in Applied Linguistics. Previous research has shown that portfolio assessment impacts learning as well as certain psychological constructs. One important factor which is related to success in learning a language is Locus of Control (LOC) introduced by Rotter (1954). Previous research has shown that EFL learners' achievement is partially related to their LOC.

However, the effect of types of assessment on General English (GE) students' LOC has scarcely been examined within General English context. This study aimed to find out the effects of portfolio assessment on the locus of control and the General English achievement of Iranian students. The researchers also analyzed the opinions of such students on portfolio assessment. To do so, 80 students of GE were divided into two groups: a control group and an experimental one. The experimental group's LOC and GE achievement were assessed through portfolios but those of the control group were assessed traditionally. Moreover, the attitudes of the experimental group students towards portfolios were explored. The independent T-test, Man-Witney U test, and Chi- square along with a semi-structured 
interview with 10 students of each group were conducted. The findings showed that portfolio assessment significantly improved GE students' LOC and affected their achievement; however, the findings did not reveal the same results for the students in the traditional group. The results of the interviews also corroborated the quantitative ones. Furthermore, the analysis of students' attitudes towards portfolio assessment showed that the experimental group students had positive attitudes towards this kind of assessment. The findings of the study are discussed within a GE context.

Key Words: Portfolio assessment, Locus of control, Alternative to assessment, GE achievement 